\title{
Association between Hemogram Parameters and Coronary Collateral Development in Subjects with Non-ST-Elevation Myocardial Infarction
}

\author{
(Di) Isa Sincer ${ }^{1}$ \\ Asli Kurtar Mansiroglu ${ }^{1}$ \\ (iD) Gulali Aktas ${ }^{2}$ \\ Dilmaz Gunes ${ }^{1}$ \\ (iD) M. Zahid Kocak ${ }^{2}$
}

1. Abant Izzet Baysal University Hospital, Department of Cardiology, Bolu, Turkey. 2. Abant Izzet Baysal University Hospital, Department of Internal Medicine, Bolu, Turkey.

http://dx.doi.org/10.1590/1806-9282.66.2.160

\section{SUMMARY}

OBJECTIVE: Coronary collateral development (CCD) predicts the severity of coronary heart disease. Hemogram parameters, such as mean platelet volume (MPV), eosinophil, red cell distribution width, and platelet distribution width (PDW), are supposed novel inflammatory markers. We aimed to compare hemogram parameter values in patients presenting with non-ST-elevation myocardial infarction (NSTEMI) with adequate or inadequate CCD.

METHODS: A total of 177 patients with NSTEMI undergoing coronary arteriography were enrolled and divided into two groups based on the development of CCD: one group with adequate $\operatorname{CCD}(n=88)$ and the other with impaired $\operatorname{CCD}(n=89)$.

RESULTS: Baseline demographics and clinical risk factors were similar between the groups. Hemogram parameters were not significantly different between the two groups. However, compared to the inadequate CCD group, the median PDW was significantly higher in the adequate CCD group, 17.6 (1.4) vs. 17.8 (1.6) $p=0.004$. In a multivariate analysis, PDW ( $p=0.001,95 \%$ Cl for OR: 0.489(0,319-0,750) was found to be significantly different in the adequate CCD group compared to the inadequate CCD group. Pearson's correlation analysis revealed that PDW was significantly correlated with the Rentrop score $(r=0.26, p<0.001)$.

CONCLUSIONS: We suggest that since PDW is an index that is inexpensive and easy to assess, it could serve as a marker of CCD in patients with NSTEMI.

KEYWORDS: Coronary collateral development, Non-ST-elevation myocardial infarction, Hematological parameters, Platelet distribution.

\section{INTRODUCTION}

Coronary collateral circulation predicts the severity of coronary heart disease. The development of coronary collateral circulation can be a herald of the prognosis of patients with coronary disease. In fact, coronary collateral development (CCD) is a response to vascular occlusion injury in coronary arteries. The establishment of CCD has been proposed to be associated with inflammatory markers, such as high-sensitivity C-reactive protein, paraoxonase activity, and asymmetric dimethylarginine.$^{1-3}$ Hemogram 
parameters, such as mean platelet volume, neutrophil to lymphocyte ratio, eosinophil, red cell distribution width, and platelet distribution width (PDW), are supposed novel inflammatory markers. An increase or decrease in their levels in hemogram assays are proposed to be related to various inflammatory conditions. Moreover, elevated PDW has been shown to be a predictor of platelet activation. ${ }^{4}$ Likewise, PDW was higher in patients with acute myocardial infarction compared to those in patients with stable coronary disease. $^{5}$

In this retrospective study, we aimed to compare hemogram parameter values in patients presenting with non-ST-elevation myocardial infarction (NSTEMI) with adequate or inadequate coronary collateral development.

\section{METHODS}

Patients with coronary heart disease admitted to cardiology clinics of our institution with a diagnosis of non-ST-elevation myocardial infarction (NSTEMI) between April 2015 and June 2018 were consecutively evaluated for the presence of coronary collateral development. To reach about $95 \%$ power and $20 \%$ variability, the minimum number of participants required in the power analysis was calculated to be 80 subjects. To protect from possible losses during the study, 10\% more subjects were included in the study. Therefore, a total of 88 patients were included in study, and 89 in the control group. The diagnosis of NSTEMI was established by the combination of the following; ischemic chest pain, a troponin-I level of $>0.01 \mathrm{ng} / \mathrm{ml}$, and absence of ST-segment elevation on 12-lead chest electrocardiography (ECG). Patients who had at least 95\% luminal narrowing in at least one major epicardial coronary artery were included. Clinical and laboratory findings were obtained from a review of the patients' files. Hypertension was defined as blood pressure $>140 / 90 \mathrm{mmHg}$ or taking antihypertensive medication. Diabetes mellitus was defined as having a fasting glucose level $\geq 126 \mathrm{mg} / \mathrm{dl}$ or using antidiabetic agents. The presence of total cholesterol $>200 \mathrm{mg} / \mathrm{dl}$ or triglyceride $>150 \mathrm{mg} / \mathrm{dl}$ was accepted as hyperlipidemia.

The exclusion criteria were as follows: malignancy, idiopathic dilated or hypertrophic cardiomyopathy, history of blood transfusion within 3 months, leukemia, thrombocytopenia, congestive heart failure, moderate to severe renal failure, history of acute myocardial infarction with ST-segment elevation, coronary artery stenting or bypass operation, coronary artery stenosis $<95 \%$, chronic obstructive pulmonary disease, severe hepatic dysfunction, atrial fibrillation, severe valvular disease, recent infection, and systemic inflammatory diseases. The study was approved by the institutional board.

Coronary angiographies were performed through the radial or femoral artery. Patients with coronary artery stenosis of $\geq 95 \%$, by visual evaluation, were included. Coronary collateral circulation was graded according to the Rentrop classification, 6 i.e., lack of filling in collateral vessels classified as Grade 0 ; filling in side branches via collateral channels without visualization of the epicardial artery classified as Grade 1; partial filling in the epicardial major coronary artery via collateral circulation classified as Grade 2; and complete filling in the epicardial major coronary artery classified as Grade 3. Two interventional cardiologists who were blinded to the study evaluated the angiographic results. The highest Rentrop grade was used for analysis in subjects with more than one coronary collateral circulation. Patients with Rentrop 0 and 1 were classified as inadequate CCD, whereas patients with Rentrop 2 and 3 were classified as adequate CCD.

Age, sex, and laboratory parameters of the participants were obtained from the database of the institution. Serum glucose, creatinine, total cholesterol, high-density lipoprotein cholesterol (HDL), low-density lipoprotein cholesterol (LDL), baseline troponin, and baseline CK-MB were measured using an automatic biochemical analyzer (Architect C8000, USA). Hemogram parameters; hemoglobin, red cell distribution width(RDW), PDW, mean platelet volume(MPV), platelet count, neutrophil, monocyte and eosinophil counts were recorded (Cell Dyn 3700; Abbott Diagnostics, Lake Forest, Illinois, USA).

Statistical analysis was conducted using SPSS software (SPSS 15.0 for Windows, IBM Co, Chicago, IL, USA). The distribution of the variables in the study groups was analyzed by the Kolmogorov-Smirnov test. The normally distributed variables were compared by the $\mathrm{t}$-test and expressed as mean \pm standard deviation. Variables that did not present normal distribution were compared using the Mann Whitney U test and expressed as median (interquartile range). The chi-square test was used to compare nonparametric variables between study groups. Pearson correlation analyses were used to assess the correlations of MPV, PDW, RDW, monocyte, and eosinophil with the 
Rentrop grade. Multivariate linear regression analysis was used to analyze the value of different baseline characteristics as independent predictors of inadequate CCD. To reveal the association of variables with adequate $\mathrm{CCD}$, we performed univariate analysis. The multivariate logistic regression model was used for variables found significant in the univariate analysis in order to determine the independent prognostic factors of adequate CCD. A p-value lower than 0.05 was considered statistically significant.

\section{RESULTS}

The study population included 177 NSTEMI patients, of whom 88 had adequate CCD and 89 had inadequate CCD. Out of the 177 patients, $56(32 \%)$ had Rentrop grade 0, 33 cases (18\%) had grade 1, 47 cases (27\%) had grade 2, and 41 cases (23\%) had grade 3. Baseline demographics and clinical risk factors were similar between the groups, except that the median age was significantly lower in the poor CCD group [66 (35-88) vs. 71 (39-90), p=0.015]. Previous medications were also comparable between the two groups (Table 1). Serum biochemistry of the subjects in the inadequate and adequate CCD groups was not statistically different; however, compared to the inadequate CCD group, creatinine $(\mathrm{p}=0.070)$ tended to be higher in the adequate CCD group (Table-2). The platelet, RDW, MPV, monocytes, eosinophil, Neutrophil, and WBC counts were not significantly different between the two groups. However, compared to the inadequate
CCD group, the median PDW was significantly higher in the adequate CCD 17.6 (1.4) vs. 17.8 (1.6) p=0.004 (Table 2). In the multivariate analysis, PDW ( $p=0.001$, 95\% CI for OR: $0.489(0,319-0,750)$ were found to be significantly different in the adequate CCD group compared to the inadequate CCD group (Table 3). Pearson's correlation analysis revealed that PDW was significantly correlated with the Rentrop score $(\mathrm{r}=0.26, \mathrm{p}<0.001)$.

\section{DISCUSSION}

The main finding of the present study is that an elevated PDW count is a possible predictor of adequate CCD in patients with NSTEMI. In the case of occlusion in a coronary vessel, myocardium may alternatively get blood flow from CCD. The development of coronary collateral circulation is affected by proximal location of stenosis, degree and severity of the stenosis, and duration of angina pectoris growth is usually categorized into angiogenesis and arteriogenesis ${ }^{7}$. New capillary development from existing capillaries is named angiogenesis, and collateral arterial development from existing arteries is named arteriogenesis. ${ }^{8}$ These vessels are thin-walled microvascular conduits, which are composed of an endothelial lining, an internal elastic lamina, and one or two layers of smooth muscle cells. ${ }^{8}$ Survival of the brain and heart mainly depend on arteriogenesis. ${ }^{9}$ Passive dilation of existing channels, rupture of the elastic lamina, and extravasation of platelets and white blood cells, including monocytes, initiates

TABLE 1. GENERAL CHARACTERISTICS OF THE STUDY GROUPS

\begin{tabular}{l|l|l|l}
\hline \multicolumn{2}{l|}{ Inadequate CCD ( $=89)$} & Adequate CCD (n=88) & \multicolumn{1}{l}{$p$} \\
\hline Age (years) & MEDIAN (IQR) & & 0.015 \\
\hline Body mass index $\left(\mathrm{kg} / \mathrm{m}^{2}\right)$ & $66(21)$ & $71(22)$ & 0.394 \\
\hline Male/female & $27.3(7.6)$ & $27.7(6.3)$ & \\
\hline Hypertension $(\%)$ & $X^{2}$ test & & 0.097 \\
\hline Smoking & $51 / 38$ & $61 / 27$ & 0.373 \\
\hline Family history & $55(62 \%)$ & $60(68 \%)$ & 0.959 \\
\hline Diabetes mellitus & $28(31 \%)$ & $28(32 \%)$ & 0.828 \\
\hline Acetyl salysilate & $10(11 \%)$ & $9(10 \%)$ & 0.923 \\
\hline Clopidogrel & $34(38 \%)$ & $33(37 \%)$ & 0.071 \\
\hline Statin & $24(27 \%)$ & $35(43 \%)$ & 0.521 \\
\hline Calcium channel blocker & $13(15 \%)$ & $10(11 \%)$ & 0.083 \\
\hline ACE inhibitor & $33(37 \%)$ & $44(50 \%)$ & 0.967 \\
\hline ARB & $21(24 \%)$ & $21(24 \%)$ & 0.237 \\
\hline B-blocker & $14(16 \%)$ & $20(23 \%)$ & 0.664 \\
\hline Note: CCD: coronary collateral development, ACE: angiotensin-converting enzyme, ARB: angiotensin receptor blocker.
\end{tabular}


arteriogenesis ${ }^{9}$. The production and release of angiogenic factors also play an important role in angiogenesis. Remodeling and proliferation of smooth muscle cells and endothelium are also needed for CCD. ${ }^{10,11}$

Platelet distribution width is a simple, easy to assess, and cheap marker of thrombocyte activation. ${ }^{4}$ It indicates varied size platelets in circulation. PDW is the size variation of platelets and a marker of platelet activation. It is more specific than MPV. ${ }^{4}$ Platelet swelling is not a fact that affects PDW. ${ }^{4}$ Elevated PDW predicts circulating mature and immature thrombocytes in the bloodstream. Abnormal thrombocytosis ${ }^{4}$ or heterogeneous demarcation of megakaryocytes ${ }^{12}$ might be responsible for elevated PDW.
Literature includes many studies on PDW in various diseases and conditions. While some authors stated the elevation of PDW was associated with the severity of preeclampsia and eclampsia, ${ }^{13}$ others emphasized the diagnostic role of PDW in pancreatic cancer. ${ }^{14}$ Type 2 diabetes mellitus is associated with higher PDW values compared to the healthy population. ${ }^{15}$ Moreover, authors have speculated that increased PDW levels could be a marker of activation in systemic lupus erythematosus. ${ }^{16}$ Authors have studied PDW in cardiac conditions, too. It has been proposed that it may enhance the prediction of the development of heart failure in subjects with acute coronary syndrome. ${ }^{17}$ In another study, PDW

TABLE 2. LABORATORY DATA OF THE STUDY GROUPS

\begin{tabular}{l|l|l|l} 
& Inadequate CCD $(\mathrm{n}=89)$ & \multicolumn{1}{l}{ Adequate CCD $(\mathrm{n}=88)$} & $\mathrm{p}$ \\
\hline & MEDIAN (IQR) & & \\
\hline Creatinine $(\mathrm{mg} / \mathrm{dl})$ & $0.93(0.37)$ & $0.97(0.39)$ & 0.070 \\
\hline Fasting plasma glucose $(\mathrm{mg} / \mathrm{dl})$ & $128(82)$ & $120(62)$ & 0.985 \\
\hline HDL-cholesterol $(\mathrm{mg} / \mathrm{dl})$ & $42(17)$ & $42(12)$ & 0.376 \\
\hline Triglyceride $(\mathrm{mg} / \mathrm{dl})$ & $114(85)$ & $129(99)$ & 0.323 \\
\hline Total cholesterol $(\mathrm{mg} / \mathrm{dl})$ & $190(63)$ & $180(81)$ & 0.821 \\
\hline Baseline troponin $[\mathrm{pg} / \mathrm{ml})$ & $10000(7400)$ & $9800(6400)$ & 0.628 \\
\hline Baseline CK-MB [IU/L] & $78(43)$ & $73(42)$ & 0.211 \\
\hline Hemoglobin $(\mathrm{gr} / \mathrm{dl})$ & $13(3.7)$ & $13.5(2.6)$ & 0.845 \\
\hline Hematocrit $(\%)$ & $39(10)$ & $41(8)$ & 0.857 \\
\hline PDW $(\%)$ & $17.6(1.4)$ & $17.8(1.6)$ & 0.004 \\
\hline RDW $(\%)$ & $16(2)$ & $17(2)$ & 0.071 \\
\hline MPV,fL & $7.6(1.7)$ & $7.5(1.3)$ & 0.586 \\
\hline WBC, $\left(\mathrm{u} / \mathrm{mm}^{3}\right)$ & $9.4(4.2)$ & $9.9(4.9)$ & 0.714 \\
\hline Eosinophil, $\left(\mathrm{u} / \mathrm{mm}^{3}\right)$ & $0.110(0.214)$ & $0.076(0.146)$ & 0.064 \\
\hline Neutrophil, $\left(\mathrm{u} / \mathrm{mm}^{3}\right)$ & $6.3(4.2)$ & $7.1(4.7)$ & 0.266 \\
\hline Monocyte, $\left(\mathrm{u} / \mathrm{mm}^{3}\right)$ & $0.61(0.30)$ & $0.60(0.43)$ & 0.738 \\
\hline & $M E A N \pm S D$ & & \\
\hline Platelet counts $\left(\mathrm{k} / \mathrm{mm}^{3}\right)$ & $243 \pm 65$ & $234 \pm 74$ & 0.423 \\
\hline LDL-cholesterol $(\mathrm{mg} / \mathrm{dl})$ & $117 \pm 44$ & $116 \pm 42$ & 0.853 \\
\hline & & & \\
\hline
\end{tabular}

PDW: platelet distribution width; RDW: Red cel distribution width; MPV: Mean platelet volume; HDL : high-density lipoprotein; LDL:low-density lipoprotein; WBC: White blood count

TABLE 3. MULTIVARIATE LOGISTIC REGRESSION ANALYSIS OF VARIABLES RELATED TO CCD

\begin{tabular}{l|l|l|l|l|l} 
Category & \multicolumn{1}{l}{ B } & \multicolumn{1}{l}{ SE } & \multicolumn{1}{l}{ WALD } & OR (95\% CI) & P-value \\
\hline RDW & -0.53 & 0.099 & 0.282 & $0.949(0.781-1.153)$ & 0.595 \\
\hline PDW & -0.715 & 0.218 & 10.740 & $0.489(0.319-750)$ & 0.001 \\
\hline MPV & 0.290 & 0.164 & 3.138 & $1.337(1843-970)$ & 0.076 \\
\hline Monocyte & -0.022 & 0.535 & 0.002 & $0.978(0.343-2.790)$ & 0.967 \\
\hline WBC & 0.140 & 0.194 & 0.520 & $1.150(0.787-1.681)$ & 0.471 \\
\hline Neutrophil & -0.157 & 0.193 & 0.660 & $0.855(0.585-1.249)$ & 0.417 \\
\hline Eosinophil & 1.577 & 1.469 & 1.153 & $4.838(0.272-86.041$ & 0.283 \\
\hline Age & -0.021 & 0.015 & 1.992 & $0.979(0.950-1.008)$ & 0.158 \\
\hline
\end{tabular}

Abbreviations: $\mathrm{SE}$, standard error; OR, odds ratio; $\mathrm{Cl}$, confidence interval. 
was introduced as a marker of the severity of the acute coronary syndrome along with a significant correlation with a high Gensini score. ${ }^{18}$ Subjects with ST-segment-elevation myocardial infarction have greater PDW values compared to subjects with stable coronary disease; 19 it is a very useful prognostic factor in long-term mortality following acute myocardial infarction ${ }^{20}$.

Inflammation is involved in atherosclerosis, atherosclerotic plaque development, and clot formation on the surface of the plaque. ${ }^{21}$ Kowara et al. ${ }^{17}$ reported that the initial PDW value on admission predicts left ventricular functions in patients with acute coronary syndrome. In another study, it has been stated that PDW could be an independent marker of ST-segment-elevation myocardial infarction. ${ }^{22}$ What causes an elevation in PDW value in patients with NSTEMI that have adequate CCD? PDW is a marker of platelet activation. Platelets activate in inflammatory conditions. Therefore, elevated PDW reflects the inflammatory burden in diseases characterized by inflammation. While coronary ischemia stimulates the development of collateral vessels, it also produces an inflammatory microenvironment. Since inflammatory cytokines stimulate angiogenesis, ${ }^{23}$ the elevated PDW in the adequate CCD group compared to the inadequate group is not surprising. Thus, elevated PDW was noticed in this subset of patients.

The association between cardiac conditions and elevated PDW is clear; however, at this point, questions arise on the measurement of PDW. EDTA in hemogram tubes might cause swelling of the thrombocytes; thus, cause also an elevation in measured PDW value. ${ }^{24}$ On the other hand, statins may have elevated PDW levels. ${ }^{25}$ All hemogram assays are done within 5 minutes from drawing blood into hemogram tubes in our institution in order to prevent platelet swelling. Moreover, the statin use in the study groups in the present report was similar. The retrospective design and relatively small study population are among other limitations of the present study. However, to the best of our knowledge, this is the first study in the literature that reported increased PDW in NSTEMI patients with adequate CCD.

\section{CONCLUSION}

We suggest that since PDW is an index that is inexpensive and easy to assess, it could serve as a marker of collateral vessel development in patients with NSTEMI.

\section{Conflict of interest \\ None}

\section{Sources of Funding}

None

\section{Author Contribution}

IS, GA, AKM designed the study; IS, MZK, YG, AKM collected the data; MZK, GA, YG performed the literature review; IS, GA, YG performed the statistical analysis; IS, GA, AKM, MZK wrote the paper; MZK, YG, GA performed the critical review of the manuscript.

\section{RESUMO}

OBJETIVO: O desenvolvimento colateral coronariano (CCD) prediz a gravidade da doença coronariana. Parâmetros de hemograma como volume plaquetário médio (VPM), eosinófilo, largura de distribuição de glóbulos vermelhos e largura de distribuição de plaquetas (PDW) são supostos novos marcadores inflamatórios. Nosso objetivo foi comparar os valores do parâmetro hemograma em pacientes com infarto do miocárdio sem supradesnivelamento do segmento ST (IAMSSST) com DCC adequado ou inadequado.

MÉTODOS: Um total de 177 pacientes com NSTEMI submetidos à arteriografia coronariana foram incluídos e divididos, com base no desenvolvimento de CCD, em dois grupos: grupo com CCD adequado $(n=88)$ e grupo com CCD alterado $(n=89)$.

RESULTADOS: Os dados demográficos e os fatores de risco clínicos basais foram semelhantes entre os grupos. Os parâmetros do hemograma não foram significativamente diferentes entre os dois grupos. Mas, em comparação com a mediana inadequada do grupo CCD, o PDW foi significativamente maior em CCD adequado de 17,6 (1,4) vs. 17,8 (1,6) p=0,004. Na análise multivariada, PDW ( $p=0,001$, IC 95\% para OR: 0,489 (0,379-0,750) foi significativamente diferente no grupo CCD adequado em comparação com o grupo CCD inadequado. A análise de correlação de Pearson revelou que PDW foi significativamente correlacionado com escore de aluguel $(r=0,26, p<0,001)$.

CONCLUSÃo: Sugerimos que, uma vez que a PDW é um índice barato e de fácil avaliação, pode servir como um marcador de DCC em pacientes com IAMSSST.

PALAVRAS-CHAVE: Desenvolvimento colateral coronário. Infarto do miocárdio sem supradesnivelamento do segmento ST. Parâmetros hematológicos. Distribuição plaquetária. 


\section{REFERENCES}

1. Kerner A, Gruberg L, Goldberg A, Roguin A, Lavie P, Lavie L, et al. Relation of $C$-reactive protein to coronary collaterals in patients with stable angina pectoris and coronary artery disease. Am | Cardiol. 2007;99(4):509-12.

2. Yildiz A, Sezen Y, Gur M, Yilmaz R, Demirbag R, Erel O. Association of paraoxonase activity and coronary collateral flow. Coron Artery Dis. 2008;19(7):441-7.

3. Kocaman SA, Sahinarslan A, Biberoglu G, Hasanoglu A, Akyel A, Timurkaynak T, et al. Asymmetric dimethylarginine and coronary collateral vessel development. Coron Artery Dis. 2008;19(7):469-74.

4. Vagdatli E, Gounari E, Lazaridou E, Katsibourlia E, Tsikopoulou F, Labrianou I. Platelet distribution width: a simple, practical and specific marker of activation of coagulation. Hippokratia. 2010;14(1):28-32.

5. Khandekar MM, Khurana AS, Deshmukh SD, Kakrani AL, Katdare AD, Inamdar AK. Platelet volume indices in patients with coronary artery disease and acute myocardial infarction: an Indian scenario. J Clin Pathol. 2006;59(2):146-9.

6. Rentrop KP, Thornton JC, Feit F, Van Buskirk M. Determinants and protective potential of coronary arterial collaterals as assessed by an angioplasty model. Am J Cardiol. 1988;61(10):677-84.

7. Fujita M, Nakae I, Kihara Y, Hasegawa K, Nohara R, Ueda K, et al. Determinants of collateral development in patients with acute myocardial infarction. Clin Cardiol. 1999;22(9):595-9.

8. Schaper W, Ito WD. Molecular mechanisms of coronary collateral vessel growth. Circ Res. 1996;79(5):911-9.

9. Buschmann I, Schaper W. Arteriogenesis versus angiogenesis: two mechanisms of vessel growth. News Physiol Sci. 1999;14:121-5.

10. Ware JA, Simons M. Angiogenesis in ischemic heart disease. Nat Med. 1997;3(2):158-64.

11. Schaper W, Görge G, Winkler B, Schaper |. The collateral circulation of the heart. Prog Cardiovasc Dis. 1988;31(1):57-77.

12. Matsuo K, Tang SH, Sharifi B, Rubin SA, Schreck R, Fagin JA. Growth factor production by human thyroid carcinoma cells: abundant expression of a platelet-derived growth factor-B-like protein by a human papillary carcinoma cell line. J Clin Endocrinol Metab. 1993;77(4):996-1004.

13. Singh A, Varma R. Role of platelet distribution width (PDW) and plateletcrit in the assessment of nonthrombocytopenic preeclampsia and eclampsia. ) Obstet Gynaecol India. 2018;68(4):289-93.
14. Ulutas KT, Sarici IS, Arpaci A. Comparison of platelet distribution width and CA19-9 in resectable pancreas cancer. Med Arch. 2018;72(3):210-3.

15. Zaccardi F, Rocca B, Pitocco D, Tanese L, Rizzi A, Ghirlanda G. Platelet mean volume, distribution width, and count in type 2 diabetes, impaired fasting glucose, and metabolic syndrome: a meta-analysis. Diabetes Metab Res Rev. 2015;31(4):402-10.

16. Chen SY, Du J, Lu XN, Xu JH. Platelet distribution width as a novel indicator of disease activity in systemic lupus erythematosus. J Res Med Sci. 2018;23:48.

17. Kowara M, Grodecki K, Huczek Z, Puchta D, Paczwa K, Rymuza B, et al. Platelet distribution width predicts left ventricular dysfunction in patients with acute coronary syndromes treated with percutaneous coronary intervention. Kardiol Pol. 2017;75(1):42-7.

18. Bekler A, Ozkan MT, Tenekecioglu E, Gazi E, Yener AU, Temiz A, et al. Increased platelet distribution width is associated with severity of coronary artery disease in patients with acute coronary syndrome. Angiology. 2015;66(7):638-43.

19. Cetin M, Bakirci EM, Baysal E, Tasolar H, Balli M, Cakici M, et al. Increased platelet distribution width is associated with ST-segment elevation myocardial infarction and thrombolysis failure. Angiology. 2014;65(8):737-43.

20. Rechcinski T, Jasinska A, Forys J, Krzeminska-Pakula M, Wierzbowska-Drabik K, Plewka M, et al. Prognostic value of platelet indices after acute myocardial infarction treated with primary percutaneous coronary intervention. Cardiol J. 2013;20(5):491-8.

21. Balta S, Celik T, Mikhailidis DP, Ozturk C, Demirkol S, Aparci M, et al. The relation between atherosclerosis and the neutrophil-lymphocyte ratio. Clin Appl Thromb Hemost. 2016;22(5):405-11.

22. Cetin MS, Ozcan Cetin EH, Akdi A, Aras D, Topaloglu S, Temizhan A, et al. Platelet distribution width and plateletcrit: novel biomarkers of ST elevation myocardial infarction in young patients. Kardiol Pol. 2017;75(10):1005-12.

23. Hu DE, Hori Y, Fan TP. Interleukin-8 stimulates angiogenesis in rats. Inflammation. 1993;17(2):135-43.

24. Pizzulli L, Yang A, Martin JF, Lüderitz B. Changes in platelet size and count in unstable angina compared to stable angina or non-cardiac chest pain. Eur Heart J. 1998;19(1):80-4.

25. De Luca G, Venegoni L, lorio S, Secco GG, Cassetti E, Verdoia M, et al; Novara Atherosclerosis Study Group. Platelet distribution width and the extent of coronary artery disease: results from a large prospective study. Platelets. 2010;21(7):508-14. 